\title{
Interest and participation in global neurosurgery: a survey of Canadian neurosurgery residents
}

\author{
Harrison J. Westwick, MD, MSc, ${ }^{1}$ Lior M. Elkaim, MD, ${ }^{2}$ Sami Obaid, MD, ${ }^{1}$ \\ Aria Fallah, MD, MSc, FRCSC, ${ }^{3}$ Albert Tu, MD, FRCSC, ${ }^{4}$ George M. Ibrahim, MD, PhD, FRCSC, ${ }^{5,6}$ \\ and Alexander G. Weil, MD, FRCSC ${ }^{1,7}$
}

\begin{abstract}
1Division of Neurosurgery, Department of Surgery, University of Montreal; '2Department of Neurosurgery, McGill University, Montreal, Quebec, Canada; ${ }^{3}$ Department of Neurosurgery, University of California, Los Angeles, California; ${ }^{4}$ Department of Neurosurgery, Children's Minnesota, St. Paul, Minnesota; ${ }^{5}$ Division of Neurosurgery, Department of Surgery, University of Toronto; ' ${ }^{D}$ ivision of Neurosurgery, The Hospital for Sick Children, The Hospital for Sick Children Research Institute, Toronto, Ontario, Canada; and 'Division of Neurosurgery, Sainte-Justine Hospital, Montreal, Quebec, Canada
\end{abstract}

OBJECTIVE The lack of access to primary neurosurgical care presents a significant burden for patients in low- and middle-income countries (LMICs). Efforts to decrease the inequities in access to surgical care have become an increasing focus of initiatives and advocacy within the international neurosurgery community. Although residents may represent highly active members of international teams, the extent of their availability for and interest in global neurosurgery opportunities remains unclear. The objectives of this study were to assess the degree of participation, the level of interest, and the perceived barriers for residents of Canadian neurosurgery programs in engaging in neurosurgery initiatives in LMICs.

METHODS A cross-sectional survey was administered to 144 residents from all accredited Canadian neurosurgery residency programs. The survey was used to determine the level of participation and interest in global neurosurgery initiatives.

RESULTS The survey response rate from residents at Canadian neurosurgery programs was 45/144 (31\%), although not all respondents answered every question; thus, the denominator for each question is not always 45 . Most neurosurgery residents $(n=30,68 \%)$ were unaware of any global neurosurgery opportunities available during residency. Despite $64 \%$ of residents having an interest in participation (strongly agree/agree; $n=28$ ), with most residents planning on participating as attending staff (strongly agree/agree; $n=28,64 \%$ ), only 3 residents $(7 \%)$ had taken part in LMIC neurosurgery initiatives. The most cited perceived limitations for participation were lack of time $(n=37,84 \%)$ and finances $(n=$ $26,59 \%)$.

CONCLUSIONS Among surveyed residents from Canadian neurosurgery programs, there was a low participation rate in global neurosurgery initiatives and limited knowledge of available opportunities, despite relatively high interest. Many respondents identified time and financial constraints as barriers to participation. Many residents felt that interest could increase were there a structured program dedicated to global neurosurgery available in their residency program. https://thejns.org/doi/abs/10.3171/2019.12.FOCUS19767

KEYWORDS global surgery; neurosurgery; low- and middle-income countries; LMIC; residency

$\mathrm{T}$ HERE has been a recent focus in the neurosurgery community on the recognition of global inequalities in access to neurosurgical care. These inequalities result in a large unmet need to address the neurosurgeryremediable disease burden in low- and middle-income countries (LMICs). ${ }^{2}$ Globally, two-thirds of the world's population may lack access to adequate surgical care; among them, there are an estimated 5 million people with treatable neurosurgical conditions. ${ }^{8}$ To help improve access to essential neurosurgical care in LMICs, the neurosurgery community has increasingly emphasized global neurosurgery initiatives, including international collaborations and humanitarian efforts?

In many surgical specialties, surgeons are more likely to participate in global surgery initiatives if they partook in similar projects during residency. ${ }^{1,3,11}$ Extrapolated to

ABBREVIATIONS LMIC = low- and middle-income country.

SUBMITTED September 23, 2019. ACCEPTED December 20, 2019.

INCLUDE WHEN CITING DOI: 10.3171/2019.12.FOCUS19767. 
neurosurgery, exposure to global neurosurgery initiatives during residency could potentially increase participation in the future, thus mitigating the worldwide burden of neurosurgical disease. Among other surgical disciplines, residents have shown interest in participating in global health electives and initiatives; however, no study exists that evaluates interest in and barriers to participation specifically among neurosurgery residents. ${ }^{1,5}$ Thus, the objective of this study was to collect data related to Canadian neurosurgery residents' participation in global neurosurgical electives or humanitarian trips to LMICs. Specifically, we sought to determine the level of interest, degree of participation, perceived barriers to participation, and strategies for increasing participation.

\section{Methods}

An online electronic survey was developed using SurveyMonkey. The survey was sent to all residents at 14 accredited Canadian neurosurgery residency training programs (144 total residents). The survey was distributed to residents via program representatives, and reminder emails were sent to each resident.

\section{Ethics}

Our institutional research ethics board waived review given the nature of the survey study.

\section{Intervention}

The survey was developed, and data were collected prospectively. A protocol was developed a priori but not registered. The survey questionnaire that was developed and used is presented in the Global Neurosurgery Survey. Questions were structured to assess demographics, knowledge of available global neurosurgery opportunities, and interest in and barriers to participating in global neurosurgery initiatives. Likert scales were used in the development of survey questions.

\section{Comparison}

The original study intended to compare the responses of residents who had and had not previously participated in LMIC initiatives. Furthermore, comparisons between Canadian and non-Canadian residents were originally intended. However, the number of respondents in these categories was too small to allow for meaningful comparisons between groups.

\section{Outcome}

The primary outcome of the study was interest in participating in international neurosurgery initiatives as measured by a Likert-like scale. Other data collected included the following: 1) baseline demographics, 2) degree of interest in and opinion of important work in LMICs, 3) actual participation in projects in LMICs, 4) perceived barriers to participation, and 5) means to enhance participation.

\section{Statistical Analysis}

The results were tabulated in a Microsoft Excel spreadsheet, and data were analyzed with IBM SPSS version 24 statistical software (IBM Corp.). Results were compared using Pearson chi-square analysis evaluating for each of the individual responses. A threshold value of $p<0.05$ was defined for statistical significance. When comparing two question responses, a Wilcoxon test was employed with a threshold of $\mathrm{p}<0.05$ for significance.

\section{Results}

\section{Demographics of Participants and Participation Rate}

The online web survey was sent to 144 residents at 14 Canadian neurosurgery residency programs. Responses were obtained from 45 residents, yielding a response rate of $31 \%$. There was at least one respondent from each Canadian residency program, and the responses were evenly distributed among residency years $(p=0.2)$. The percentages cited in the abstract and text are based on the number of responses to the individual questions. Participants did not answer all of the questions, and often there was one person who would not answer a given question. Thus, the denominator is not always 45 .

The demographics of the residents surveyed were comparable to other Canadian neurosurgery residency surveys conducted in Canada. ${ }^{14}$ The overall demographics of survey responders are presented in Table 1 .

The nationality of responders was recorded to be Canadian for 33 (73\%), non-Canadian for 8 (18\%), and dual citizens for $4(9 \%)$ residents. Most responders were born in Canada $(\mathrm{n}=29,64 \%)$ or Saudi Arabia $(\mathrm{n}=6,13 \%)$. Thirty-seven responders $(82 \%)$ were Canadian medical school alumni, while the remaining $8(18 \%)$ had obtained their medical degrees outside of Canada. Thirty-five respondents (78\%) spoke two or more languages, with 10 $(22 \%)$ speaking three or more languages $(\mathrm{p}<0.01)$.

\section{Training Opportunities and Participation in LMICs in Canadian Residency Programs}

Thirty residents $(68 \%)$ stated that they were unaware of any global neurosurgery opportunities in LMICs available during residency. With regard to faculty participation in global health projects, most responders stated that there were no faculty members involved in global health projects $(\mathrm{n}=18,42 \%)$. The number of faculty involved in global health initiatives within the program included 1 (n $=11,26 \%), 2(\mathrm{n}=9,21 \%)$, and greater than $2(\mathrm{n}=5,12 \%)$ faculty. Most residents $(n=36,80 \%)$ believed that their program had a neutral outlook on resident global neurosurgery participation. Six residents (13\%) felt that their program discouraged participation, while only 3 residents (7\%) felt that their program encouraged participation $(\mathrm{p}<$ 0.01; Fig. 1).

Of all surveyed residents, 36 (80\%) believed that they could have a positive local impact abroad. Only $2(4 \%)$ disagreed, while no participant strongly disagreed. Furthermore, $36 \%$ of residents surveyed $(n=16)$ planned on participating in a global neurosurgery rotation during the remainder of their residency. Despite these results, only 3 residents (7\%) had previous hands-on experience in global neurosurgery initiatives $(\mathrm{p}<0.01)$. These opportunities were described in free-text responses as research in 2 cases and teaching in 1 case. 
TABLE 1. Demographics of Canadian neurosurgery resident respondents

\begin{tabular}{|c|c|}
\hline Demographic & Number (\%) \\
\hline \multicolumn{2}{|l|}{ Sex } \\
\hline Male & $36(80 \%)$ \\
\hline Female & $9(20 \%)$ \\
\hline \multicolumn{2}{|l|}{ Age (years) } \\
\hline$<25$ & $3(7 \%)$ \\
\hline $25-29$ & $23(51 \%)$ \\
\hline $30-34$ & $17(38 \%)$ \\
\hline $35-39$ & $2(4 \%)$ \\
\hline$\geq 40$ & 0 \\
\hline \multicolumn{2}{|l|}{ Residency year } \\
\hline 1 & $10(22 \%)$ \\
\hline 2 & $6(13 \%)$ \\
\hline 3 & $7(16 \%)$ \\
\hline 4 & $7(16 \%)$ \\
\hline 5 & $9(20 \%)$ \\
\hline 6 & $5(11 \%)$ \\
\hline$\geq 7$ & $1(2 \%)$ \\
\hline \multicolumn{2}{|l|}{ Children } \\
\hline Yes & $9(20 \%)$ \\
\hline No & $36(80 \%)$ \\
\hline \multicolumn{2}{|l|}{ Nationality } \\
\hline Canadian & $33(73 \%)$ \\
\hline Dual Canadian \& other & $4(9 \%)$ \\
\hline Outside of Canada & $8(18 \%)$ \\
\hline \multicolumn{2}{|l|}{ Residency program } \\
\hline University of British Columbia & $1(2 \%)$ \\
\hline University of Alberta & $5(11 \%)$ \\
\hline University of Calgary & $5(11 \%)$ \\
\hline University of Saskatchewan & $1(2 \%)$ \\
\hline University of Manitoba & $1(2 \%)$ \\
\hline Western University & $2(4 \%)$ \\
\hline McMaster University & $5(11 \%)$ \\
\hline University of Toronto & $5(11 \%)$ \\
\hline University of Ottawa & $3(7 \%)$ \\
\hline McGill University & $4(9 \%)$ \\
\hline University of Montreal & $5(11 \%)$ \\
\hline University of Sherbrooke & $2(4 \%)$ \\
\hline Laval University & $4(9 \%)$ \\
\hline Dalhousie University & $2(4 \%)$ \\
\hline \multicolumn{2}{|l|}{ Advanced degree* } \\
\hline MSc & $8(19 \%)$ \\
\hline $\mathrm{PhD}$ & $8(19 \%)$ \\
\hline None & $27(63 \%)$ \\
\hline \multicolumn{2}{|l|}{ No. of languages spoken } \\
\hline 1 & $10(22 \%)$ \\
\hline 2 & $25(56 \%)$ \\
\hline 3 & $9(20 \%)$ \\
\hline$>3$ & $1(2 \%)$ \\
\hline
\end{tabular}

* Two participants did not respond to the question about advanced degrees.

\section{Interest in Global Neurosurgery}

Overall, $64 \%$ of residents $(n=28)$ were interested in participating in a global neurosurgery rotation during residency (strongly agree or agree), while $16 \%(n=7)$ were not interested (disagree or strongly disagree). Nineteen residents (42\%) felt that increasing global access to neurosurgical care would be a future career priority (strongly agree or agree), with 28 residents (64\%) planning on participating in global neurosurgery initiatives as staff neurosurgeons (strongly agree or agree). The proportion of residents that either disagreed or strongly disagreed that global neurosurgery initiatives would be a future career priority were $16 \%(\mathrm{n}=7)$ and $4 \%(\mathrm{n}=2)$, respectively (Fig. 2). The most common response for an ideal global neurosurgery rotation duration was $2-4$ weeks $(\mathrm{n}=24,55 \%)$, followed by $1-2$ weeks $(n=9,20 \%)$ and 0 weeks $(n=6$, $14 \%)$. Generally, respondents were interested in initiatives with clinical and surgical exposure $(n=41,93 \%)$, teaching $(\mathrm{n}=26,59 \%)$, research $(\mathrm{n}=15,34 \%)$, and observation opportunities $(\mathrm{n}=5,11 \%)$.

The majority of residents agreed or strongly agreed that they were interested in participating in a global neurosurgery rotation during their residency $(\mathrm{n}=28,64 \%)$; however, when asked if they planned to participate during their remaining residency, there were fewer residents who agreed or strongly agreed $(\mathrm{n}=16,36 \%)$. Wilcoxon analysis showed this difference to be statistically significant $(\mathrm{p}$ $=0.01)$. Most residents agreed or strongly agreed that they planned to participate in a global neurosurgery rotation as a consultant neurosurgeon $(\mathrm{n}=28,64 \%)$. Interpretation of the lower rates of residents planning to participate compared to the number of interested residents could be explained by a ceiling effect. Fifteen (33\%) respondents were in their fifth year or later of residency and therefore could not participate in their remaining residency.

\section{Opinions on Global Neurosurgery}

Most residents believed that global neurosurgery is a recognized potential career track, on par with neurosurgeon-educator and neurosurgeon-scientist titles. Twentyfour responders (53\%) agreed or strongly agreed, 12 (27\%) were neutral, and 9 (20\%) disagreed, with no resident strongly disagreeing $(\mathrm{p}=0.007)$. Motivating factors for participation included cultural experience $(\mathrm{n}=35,80 \%)$, altruistic goal $(n=30,68 \%)$, enhancing clinical/technical exposure $(\mathrm{n}=30,68 \%)$, personal goal $(\mathrm{n}=23,52 \%)$, building personal contacts $(n=23,52 \%)$, enhancing curriculum vitae $(\mathrm{n}=15,34 \%)$, and learning new languages $(\mathrm{n}=7$, $16 \%)$.

\section{Barriers to Participation in Global Neurosurgery}

The most cited barriers to participation were lack of time $(n=37,84 \%)$, financial concerns $(n=26,59 \%)$, fear of missing training at home $(\mathrm{n}=21,48 \%)$, family/social limitations $(\mathrm{n}=20,45 \%)$, lack of program support $(\mathrm{n}=$ $16,36 \%$ ), fear of missing electives for fellowship/career $(\mathrm{n}=15,34 \%)$, and lack of available opportunities $(\mathrm{n}=15$, $34 \%)$. Other limiting factors were programs not willing to give time/remove from call schedule $(\mathrm{n}=13,30 \%)$, fear of local diseases $(n=5,11 \%)$, hospital conditions $(n=5$, 

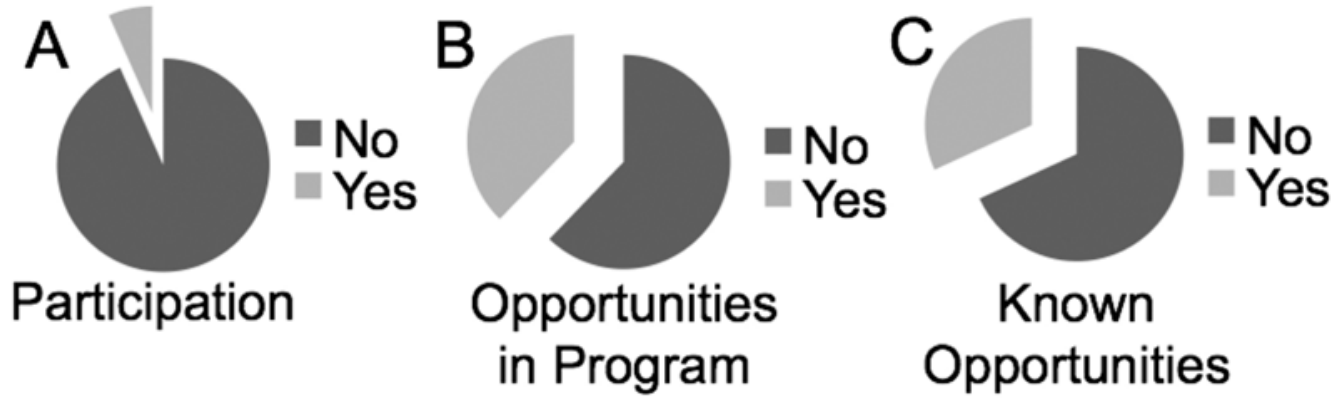

FIG. 1. Actual participation of residents (A), proportion of residents with known opportunities in their program (B), and proportion of residents aware of opportunities in LMICs (C).

$11 \%)$, living conditions $(\mathrm{n}=5,11 \%)$, personal safety $(\mathrm{n}=4$, $9 \%)$, and fear of inexperience $(\mathrm{n}=4,9 \%)$. The perceived barriers to participation in global neurosurgery initiatives among survey responders are presented in Fig. 3.

When asked if they would use personal vacation to participate, 4 residents (9\%) strongly agreed, $13(30 \%)$ agreed, 5 (11\%) were neutral, $16(36 \%)$ disagreed, and 6 $(14 \%)$ strongly disagreed $(\mathrm{p}=0.01)$. Responses were also divided with respect to personally funding their involvement: 2 (5\%) strongly agreed, 14 (32\%) agreed, 8 (18\%) were neutral, 15 (34\%) disagreed, and 5 (11\%) strongly disagreed $(\mathrm{p}=0.006)$.

\section{Means to Increase Participation}

Thirty-seven respondents $(86 \%)$ believed that funding opportunities could increase resident participation in LMIC rotations. Similarly, residents indicated that dedicated elective time to participate $(n=37,86 \%)$ or staff in- volvement from their home institution $(n=28,65 \%)$ could increase participation. Most residents also felt that a structured program during residency would increase interest in participation (Fig. 4). Regarding implementation of a structured program during residency, 17 (40\%) were very interested, $16(37 \%)$ were interested, 8 (19\%) were neutral, $1(2 \%)$ was uninterested, and $1(2 \%)$ was very uninterested $(\mathrm{p}<0.01)$.

\section{Discussion}

\section{Resident Interest}

Interest in global surgical initiatives has been demonstrated among residents from other surgical disciplines. ${ }^{5,13,15}$ One survey conducted among American general surgery residents showed that $92 \%$ of respondents had an interest in participating in an international elective, and $85 \%$ of respondents intended to include volunteerism in

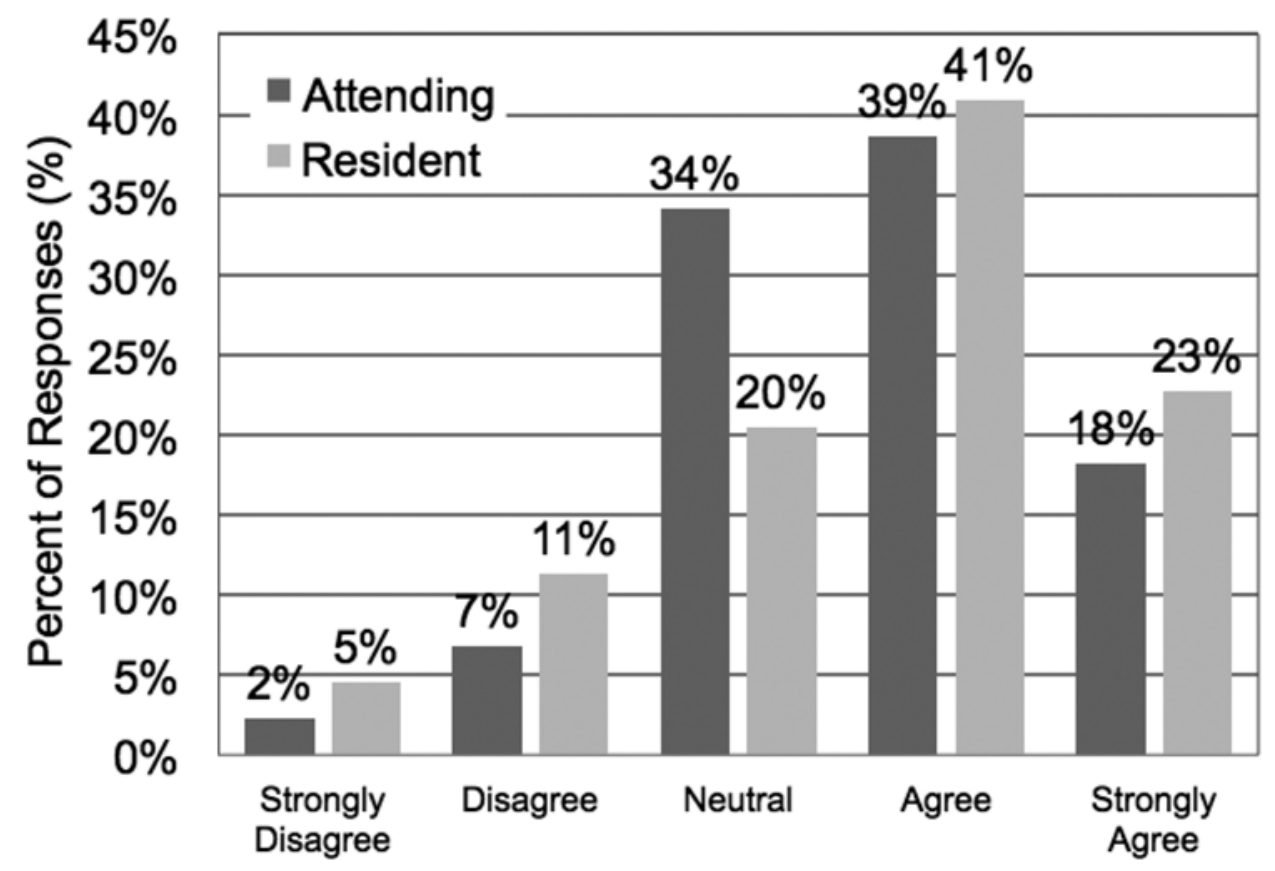

FIG. 2. Comparison of the interest in participating in global neurosurgery initiatives as a resident versus potentially after graduating from residency as an attending. 


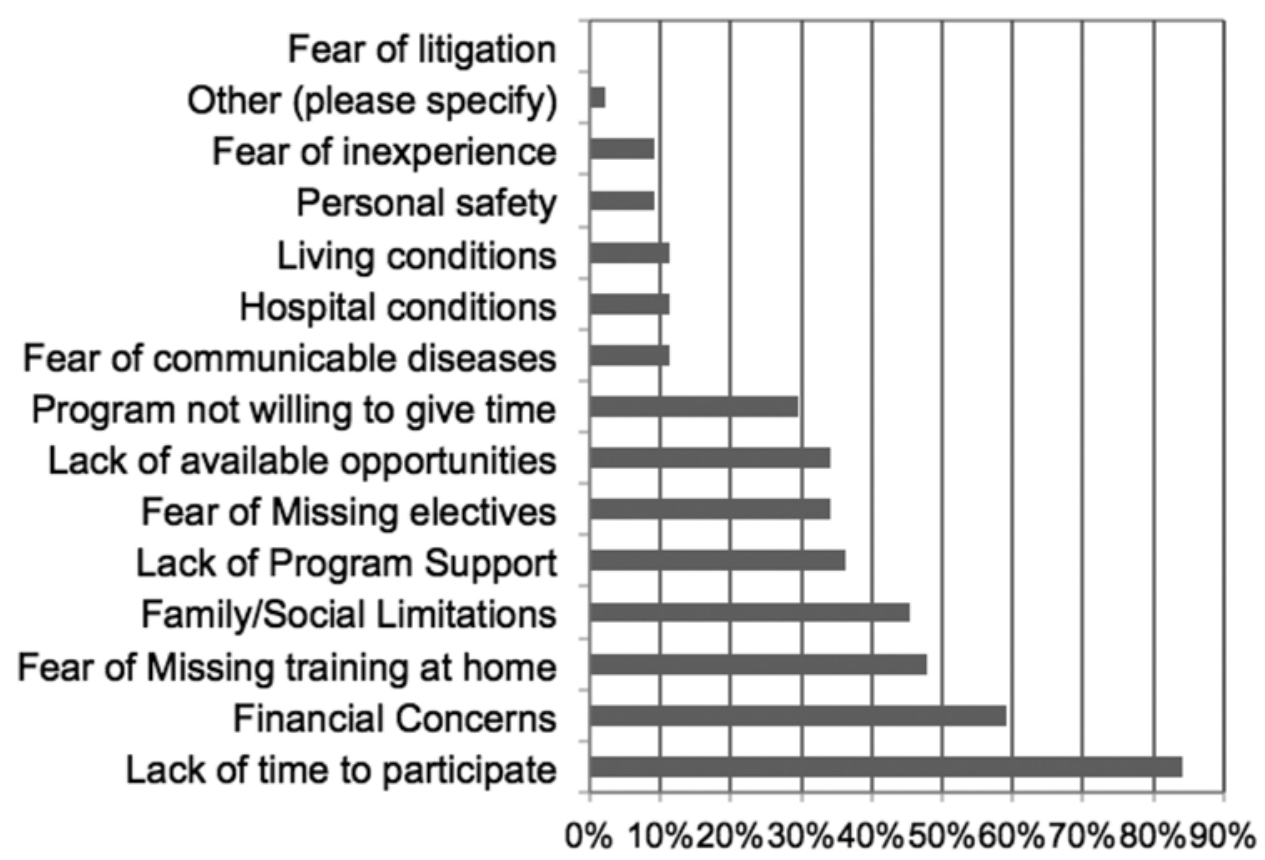

FIG. 3. Perceived barriers to participation in global neurosurgery initiatives.

their future practice. ${ }^{14}$ This study likewise demonstrated a strong interest in global surgery initiatives among residents, with $57 \%$ of residents having an interest in participating during residency and 64\% planning on participating as future attending staff. Notably, most residents also felt that they could have a positive impact abroad (strongly agree/agree; $n=36,80 \%$ ). Despite the relatively high interest, only $7 \%$ of surveyed neurosurgery residents had previously been involved in global health initiatives. These results are similar to those from other Canadian resident surveys, with only $5.1 \%$ of general and orthopedic surgery residents stating they had previously participated in global surgery initiatives, despite almost $64 \%$ of residents claiming interest. ${ }^{13}$ Although neurosurgery resident participation seems low, evidence exists supporting an increase in participation as faculty; in a survey conducted among pediatric neurosurgeons, $61 \%$ of respondents stated they had participated in surgery or teaching in developing countries, with $49 \%$ participating annually?

Resident participation, however, has not been a focus of significant discussion. Many ethical concerns of residents participating in international humanitarian rotations have been thoroughly discussed.,

The availability of global health initiatives varies widely in other specialties. One recent study among surveyed US residents showed that the specialties with the highest percentage of programs offering global health opportunities were preventative medicine $(83 \%)$, emergency medicine (74\%), and general surgery (71\%). The specialties with the lowest percentage were obstetrics (28\%) and orthopedic surgery (21\%)..$^{10}$ Comparatively, our results showed that $68 \%$ of surveyed neurosurgery residents were unaware of global neurosurgery opportunities, while $62 \%$ stated that there were no opportunities throughout residency. Despite these responses, many neurosurgical education initiatives in LMICs exist and include, among others, assisting in the development of neurosurgical boot camps ${ }^{1}$ and residency training programs. ${ }^{6,15,17}$

\section{Motivating Factors}

Cultural experiences, altruistic and personal goals, enhancing technical skill, and building new contacts were some of the primary motivating factors to participation identified in the present study. Similarly, residents from other surgical specialties identified contribution to a cause, enhancing technical skill, and exploring volunteering opportunities as reasons for participation. ${ }^{13}$ Many benefits exist for participating in global neurosurgery initiatives, including, among others, reduction of local neurosurgery

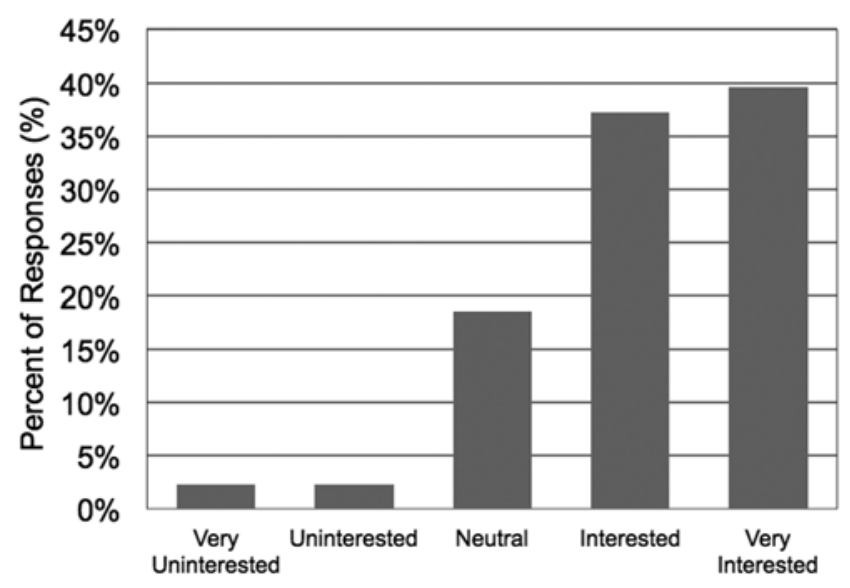

FIG. 4. Interest in participating in global neurosurgery initiatives among Canadian residents if a structured program existed in their residency. 
disease burden, assisting in the development of local neurosurgery training programs, transferring knowledge, and creating relationships between communities. However, the advantages of participation in global neurosurgery in LMICs are not limited to the effects on the local populations and can positively impact residents, faculty members, and entire residency programs. These benefits may include increased surgical exposure to rare advanced pathologies not often seen in high-income countries, learning to adapt in an environment with fewer resources, developing an international professional network, and increasing cultural sensitivity and social awareness. ${ }^{1}$ Some authors have even suggested that programs that offer these opportunities during residency can influence recruitment of top candidates. ${ }^{15}$ In a Canadian survey of general surgery and orthopedic residents, half of the respondents stated that the presence of a global surgery program would positively influence their choice of residency program..$^{13}$ As focus on global surgery increases in the international community, the academic value of global surgical participation will continue to be recognized, ${ }^{12,16}$ and careers centered on global surgery will be increasingly celebrated. This sentiment was reflected in the present study, with most residents recognizing global neurosurgery as a legitimate career path, on par with scientist and educator roles.

\section{Barriers to Participation}

Many barriers to participation were identified by the residents in this study, including, among others, time constraints, family or social limitations, lack of program support, and fear of detrimental effects on fellowship or career. Most of these concerns, including time constraints, the concern that participation will interfere with future career/fellowship goals, and lack of program support, were identified as barriers among general and orthopedic surgery residents in another survey study. ${ }^{13} \mathrm{~A}$ recent systematic review of global health residency opportunities among various medical and surgical specialties highlighted consistently reported challenges related to funding, supervision, scheduling difficulties, accreditation, and lack of sufficient infrastructure. ${ }^{10}$ To address the frequently cited time limitations, some residents have turned to using vacation or other personal time to participate in global surgery initiatives. ${ }^{11}$ When evaluating this option among neurosurgery residents in this study, the results were mixed: $39 \%$ of residents would use personal time to participate in global surgery initiatives, while $50 \%$ would not.

Another significant perceived barrier to participation identified in this study was financial concern. Despite the existence of certain funding opportunities, many residents and faculty cover their expenses when participating in LMIC electives.? Financial concerns were also identified as a barrier to participation among otorhinolaryngology residents, who would often use personal funds to participate in global surgery electives. ${ }^{11}$ Personal safety concerns and fear of contracting diseases were less frequently cited barriers to participation, among both the neurosurgery residents in this study and surgical residents from other surveys. ${ }^{14}$

Perceived barriers to participation in global neurosurgery initiatives are not limited to residents. A recent study evaluating international volunteerism in neurosurgery identified many challenges encountered by staff neurosurgeons; these included local collaboration and limitations related to equipment or infrastructure..$^{15}$ The authors suggested that completion of future missions will rely on enhancing the continuity of care, improving institutional relationships, and acquiring donations to deal with infrastructure limitations..$^{15}$ Another recent study by Fallah and Bernstein ${ }^{9}$ analyzed barriers to participation in global neurosurgery academic initiatives. They identified 3 main barrier themes: individual, community, and system. Individual barriers focused on loss of income, family, career, skepticism, and concerns for safety. Community barriers were mainly insufficient mentorship, early exposure, and support from colleagues. Finally, system barriers were related to time, academic recognition, awareness of opportunities, administrative support, and funding.

\section{Means of Increasing Participation}

According to the residents in the present study, addressing the previously discussed barriers may increase participation in global neurosurgery initiatives. Specifically, residents responded that offering dedicated time or financial support could increase participation. The residents also highlighted the need for positive role models. The "top-down" provision of staff members who are engaged in global neurosurgery may be a means of increasing participation among residents. Finally, the development of a structured program could substantially increase resident exposure.

\section{Limitations}

Participation in the resident survey was optional; thus, the results may be limited by selection bias for residents with interest in participating in global neurosurgery initiatives. Despite the possible selection bias, the overall response rate was $31 \%$, with resident representation from all Canadian residency programs and an even distribution of residents among training years. Furthermore, assessing the state of participation and opportunities for international participation was self-reported by the survey respondents and was not corroborated. The survey was, however, designed to examine residents' perspectives and interests and was not intended to collect quantitative data regarding participation rates and the type and extent of participation by attending staff. Another limitation is that the initial survey design comparing responses between residents with prior global neurosurgery experience and those with no prior experience was not feasible due to the low number of participants with prior experience. This limited the evaluation of one of the hypotheses that prior experience would increase future participation.

Furthermore, interpretation of the discrepancy between the disproportionately higher interest in global health after residency compared to during residency may be biased by the number of respondents in their final years who are unable to participate in a rotation in their remaining years of training.

There has been recent focus on and interest in burnout and resiliency in medicine and specifically in neurosurgery, and exploring the perceived roles of humanitarian 
work in protecting against burnout and increasing diversity in one's career could be an interesting focus of future study.

\section{Conclusions}

There is significant interest in participating in neurosurgery initiatives in LMICs among Canadian neurosurgery residents, with most residents expressing the positive potential impact they could have abroad. Despite the expressed interest, actual participation in these initiatives is low. The most common perceived barriers to participation were time constraints and financial concerns, followed by fear of missing training at home and family/social constraints. The means to enhancing participation include dedicated time, financial support, and the presence of an attending neurosurgeon from their institution. Residents felt that if a structured program existed in their program, it would enhance interest in participation.

\section{References}

1. Aziz SR, Ziccardi VB, Chuang SK: Survey of residents who have participated in humanitarian medical missions. J Oral Maxillofac Surg 70:e147-e157, 2012

2. Barthélemy EJ, Benjamin E, Edouard Jean-Pierre MY, Poitevien $\mathrm{G}$, Ernst $\mathrm{S}$, Osborn I, et al: A prospective emergency department-based study of pattern and outcome of neurologic and neurosurgical diseases in Haiti. World Neurosurg 82: $948-953,2014$

3. Bauer I: More harm than good? The questionable ethics of medical volunteering and international student placements. Trop Dis Travel Med Vaccines 3:5, 2017

4. Bernstein M: Ethical dilemmas encountered while operating and teaching in a developing country. Can J Surg Jun 47:170-172, 2004

5. Butler MW, Krishnaswami S, Rothstein DH, Cusick RA: Interest in international surgical volunteerism: results of a survey of members of the American Pediatric Surgical Association. J Pediatr Surg 46:2244-2249, 2011

6. Coburger J, Leng LZ, Rubin DG, Mayaya G, Medel R, Ngayomela I, et al: Multi-institutional neurosurgical training initiative at a tertiary referral center in Mwanza, Tanzania: where we are after 2 years. World Neurosurg 82:e1-e8, 2014

7. Davis MC, Rocque BG, Singhal A, Ridder T, Pattisapu JV, Johnston JM Jr: State of global pediatric neurosurgery outreach: survey by the International Education Subcommittee. J Neurosurg Pediatr 20:204-210, 2017

8. Dewan MC, Rattani A, Fieggen G, Arraez MA, Servadei F, Boop FA, et al: Global neurosurgery: the current capacity and deficit in the provision of essential neurosurgical care. Executive Summary of the Global Neurosurgery Initiative at the Program in Global Surgery and Social Change. J Neurosurg 130:1055-1064, 2019

9. Fallah PN, Bernstein M: Barriers to participation in global surgery academic collaborations, and possible solutions: a qualitative study. J Neurosurg 130:1157-1165, 2019
10. Hau DK, Smart LR, DiPace JI, Peck RN: Global health training among U.S. residency specialties: a systematic literature review. Med Educ Online 22:1270020, 2017

11. Jafari A, Tringale KR, Campbell BH, Husseman JW, Cordes SR: Impact of humanitarian experiences on otolaryngology trainees: a follow-up study of travel grant recipients. Otolaryngol Head Neck Surg 156:1084-1087, 2017

12. Krishnaswami S, Stephens CQ, Yang GP, Nwomeh BC, Swaroop M, Nadler EP, et al: An academic career in global surgery: a position paper from the Society of University Surgeons Committee on Academic Global Surgery. Surgery 163:954-960, 2018

13. Matar WY, Trottier DC, Balaa F, Fairful-Smith R, Moroz P: Surgical residency training and international volunteerism: a national survey of residents from 2 surgical specialties. Can J Surg 55:S191-S199, 2012

14. Powell AC, Casey K, Liewehr DJ, Hayanga A, James TA, Cherr GS: Results of a national survey of surgical resident interest in international experience, electives, and volunteerism. J Am Coll Surg 208:304-312, 2009

15. Sedney CL, Siu J, Rosseau G, Dempsey R, Bernstein M: International neurosurgical volunteerism: a temporal, geographic, and thematic analysis of foundation for international education in neurological surgery volunteer reports. World Neurosurg 82:963-968, 2014

16. Swain JD, Matousek AC, Scott JW, Cooper Z, Smink DS, Bolman RM III, et al: Training surgical residents for a career in academic global surgery: a novel training model. J Surg Educ 72:e104-e110, 2015

17. Weil AG, Fallah A, Bhatia S, Ragheb J: Pediatric neurosurgery in the developing world: the Haiti experience. J Craniofac Surg 26:1061-1065, 2015

\section{Disclosures}

The authors report no conflict of interest concerning the materials or methods used in this study or the findings specified in this paper.

\section{Author Contributions}

Conception and design: Westwick, Obaid, Weil. Acquisition of data: Weil. Drafting the article: Westwick, Elkaim, Weil. Critically revising the article: Fallah, Tu, Ibrahim, Weil. Reviewed submitted version of manuscript: Westwick. Approved the final version of the manuscript on behalf of all authors: Westwick. Statistical analysis: Westwick.

\section{Supplemental Information \\ Online-Only Content \\ Supplemental material is available online. Global Neurosurgery Survey. https://thejns.org/doi/suppl/ 10.3171/2019.12.FOCUS19767.}

\section{Correspondence}

Harrison J. Westwick: University of Montreal, QC, Canada. harrison.westwick@umontreal.ca. 